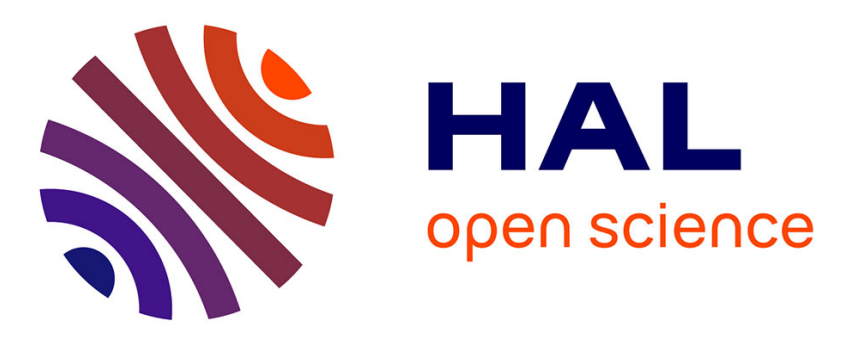

\title{
Temporal evolution of age data under transient pumping conditions
}

Sarah Leray, Jean-Raynald de Dreuzy, Luc Aquilina, Virginie

Vergnaud-Ayraud, Thierry Labasque, Olivier Bour, Tanguy Le Borgne

\section{To cite this version:}

Sarah Leray, Jean-Raynald de Dreuzy, Luc Aquilina, Virginie Vergnaud-Ayraud, Thierry Labasque, et al. Temporal evolution of age data under transient pumping conditions. Journal of Hydrology, 2014, 511, pp.555-566. 10.1016/j.jhydrol.2014.01.064 . insu-00952724

\section{HAL Id: insu-00952724 https://hal-insu.archives-ouvertes.fr/insu-00952724}

Submitted on 28 Feb 2014

HAL is a multi-disciplinary open access archive for the deposit and dissemination of scientific research documents, whether they are published or not. The documents may come from teaching and research institutions in France or abroad, or from public or private research centers.
L'archive ouverte pluridisciplinaire HAL, est destinée au dépôt et à la diffusion de documents scientifiques de niveau recherche, publiés ou non, émanant des établissements d'enseignement et de recherche français ou étrangers, des laboratoires publics ou privés. 


\section{Temporal evolution of age data under transient pumping conditions}

2 Authors: Leray S. ${ }^{1,}{ }^{*}, \#$, de Dreuzy J.-R. ${ }^{1,2}$, Aquilina L. ${ }^{1}$, Vergnaud-Ayraud V. ${ }^{1}$, Labasque T. ${ }^{1}$, 3 Bour O. ${ }^{1}$, Le Borgne T. ${ }^{1}$.

${ }^{1}$ Géosciences Rennes (UMR 6118 CNRS), Université de Rennes 1, Campus de Beaulieu, $6 \quad 35042$ Rennes cedex, France

$7 \quad{ }^{2}$ IDAEA (CSIC), c/ Jordi Girona, 08034, Barcelona, Spain

$8 \quad *$ Corresponding author: sarah.leray1@gmail.com

9 \# Now at: IFP Energies nouvelles, 1-4, avenue de Bois-Préau, 92852 Rueil-Malmaison, 10 France

Key words: groundwater age, residence time distribution, environmental tracers, 13 chlorofluorocarbons, heterogeneous aquifers, transient flow conditions

\section{Abstract}

While most age data derived from tracers have been analyzed in steady-state flow conditions,

17 we determine their temporal evolution when starting a pumping. Our study is based on a model made up of a shallowly dipping aquifer overlain by a less permeable aquitard

19 characteristic of the crystalline aquifer of Plœmeur (Brittany, France). Under a pseudo transient flow assumption (instantaneous shift between two steady-state flow fields), we solve

21 the transport equation with a backward particle-tracking method and determine the temporal 
evolution of the concentrations at the pumping well of CFC-11, CFC-12, CFC-113 and SF 6 . Apparent ages evolve because of the modifications of the flow pattern and because of the nonlinear evolution of the tracer atmospheric concentrations. To identify the respective role of these two causes, we propose two successive analyses. We first convolute residence time distributions initially arising at different times at the same sampling time. We secondly convolute one residence time distribution at various sampling times. We show that flow pattern modifications control the apparent ages evolution in the first pumping year when the residence time distribution is modified from a piston-like distribution to a much broader distribution. In the first pumping year, the apparent age evolution contains transient information that can be used to better constrain hydrogeological systems and slightly compensate for the small number of tracers. Later, the residence time distribution hardly evolves and apparent ages only evolve because of the tracer atmospheric concentrations. In this phase, apparent age time-series do not reflect any evolution in the flow pattern.

\section{Introduction}

Groundwater flow is by nature transient, because of the temporal variations of boundary conditions such as the variations of recharge over different time scales (seasons, decades, centuries or more) and because of anthropogenic forcings such as pumping or artificial recharge. Pumping has a significant impact on the flow pattern and on solute transport. They induce more convergent flow pattern and, even in some cases, some extension of recharge areas (Bredehoeft, 2002; Frind et al., 2005). It will as well speed up flows and modify the relative role of structures, hydrodynamic properties and boundary conditions - increasing for instance the effective recharge rate of unconfined aquifers in close connection to the surface (Leray et al., 2012; Sophocleous, 2005). 
Environmental tracers have been widely used for water sources identification, estimation of residence time distribution and model calibration amongst others (Castro et al., 1998; Cook et al., 2005; Long and Putnam, 2009; McMahon et al., 2010; Stichler et al., 2008). Because they integrate velocities along flow paths, they reflect flow conditions over various time scales in the past. They are sensitive to transient phenomena affecting the flow field. More precisely, they are sensitive to transient phenomena occurring over time scales comparable to their characteristic time (Zuber et al., 2011).

Yet, the influence of transient flow conditions on environmental tracer concentration has hardly been addressed. Sanford et al. (2004) have reconstructed transient recharge rates using ${ }^{14} \mathrm{C}$ data in the regional alluvial middle Rio Grande Basin. Schwartz et al. (2010) have noticed that the interpretation of ${ }^{14} \mathrm{C}$ age in transient flow models can be ambiguous in terms of flow pattern as data distributed over the aquifer reflect different flow conditions. Long and Putnam (2009) have incorporated CFCs and ${ }^{3} \mathrm{H}$ data from a karstic system in binary mixing model with dilution allowing parameters to vary with time. Fewer studies have analyzed the role of transient flow conditions on residence time distribution. Using numerical simulations, Troldborg et al. (2008) have showed the effect of recharge seasonality on residence time distribution and have noticed distinct behaviors. In the shallowest part of the studied heterogeneous aquifer, residence times tend to be smaller than in steady-state flow conditions while they tend to be higher in the deepest part of the aquifer. The effect in a fully-penetrating well is however negligible. Zinn and Konikow (2007) have analyzed the effect of the start of pumping on a synthetic configuration composed of an aquifer overlain by an aquitard. Their study have revealed important changes of the mean residence time at the pumping well and of the residence time distribution over long periods of time. Changes only come from the 
modification of the flow pattern as they solely focused on the mean residence time and not on the apparent ages obtained from tracers.

In this study, we determine the influence of the transient groundwater flow pattern induced by anthropogenic forcing on environmental tracers concentrations (CFC-11, CFC-12, CFC-113 and $\mathrm{SF}_{6}$ ) interpreted in apparent ages. We consider that the transient flow pattern is induced by the instantaneous start of a pumping well. Tracer concentrations are reported at the pumping well. Our study is based on the hydrogeological setting of Plœmeur, which is a well documented aquifer where water has been produced for the last two decades for the water supply of the nearby city (Le Borgne et al., 2004; Le Borgne et al., 2006; Ruelleu et al., 2010; Touchard, 1999). Although based on a specific site, the results of this study can be generalized to shallowly dipping aquifers overlain by a leaking layer. Such condition has been proved to be of importance for groundwater resources in hard-rock aquifers (Leray et al., 2013). While our objective is more methodological than targeted to a specific site, the Plœmeur aquifer still offers a complex and yet realistic hydrodynamic context. We use hydrogeological models previously calibrated in steady-state flow conditions under pumping (Leray et al., 2012) and determine the effect of transient flow conditions on apparent ages. We first aim at determining the causes of the temporal evolution of the apparent ages and specifically when they rather come from the transient modifications of the flow pattern and when they are more linked to the specificities of the tracers, especially their atmospheric concentrations. We second aim at assessing the interest of age data time series for models segregation. After recalling in section 2 the hydrogeological, flow and transport models, we present the results in section 3 and discuss them in section 4. 
We successively describe the hydrogeological models of the Plœmeur site that will be used as a basis of this study, the flow and the transport models as well as the numerical methods used. We finally comment in details the derivation of the tracer concentrations and the corresponding apparent ages to highlight the possible causes of apparent age temporal variations.

\subsection{Hydrogeological model}

The study of the effects of transient flow conditions, induced by pumping, on age data is based on the Plœmeur aquifer, a highly heterogeneous hard-rock aquifer located on the south coast of Brittany near the city of Lorient (France). A previous study based on the inversion of

100 gravimetric data has established a geological conceptual model (Ruelleu et al., 2010). This conceptual model is composed of two transmissive structures at large scale, the dipping contact zone and a North $20^{\circ}$ normal fault, besides the Plœmeur and Guidel granites and overlying micaschists acting as a typical aquitard. Local heterogeneities are not represented in

104 the model. The supplying area to the pumping well which amounts to a few square kilometers

105 is limited in the North-South direction by these two granites. The pumping rate thus has a strong impact on flow pattern within this heterogeneous aquifer.

107 Because the shape and the dip of the contact zone are only partially known, the overall

108 thickness of the aquitard-aquifer system remains relatively uncertain. To account for this 109 uncertainty, a few structural models with distinct thickness have been built (Figure 1 and 110 Table 1). The hydraulic properties of the different rocks have been set either to common 111 values as for the granites which are found almost impervious $\left(10^{-11} \mathrm{~m} / \mathrm{s}\right)$, or to measured 112 values as for the micaschists $\left(10^{-7} \mathrm{~m} / \mathrm{s}-5 \times 10^{-6} \mathrm{~m} / \mathrm{s}\right)$ and the contact zone $\left(1.9 \times 10^{-3} \mathrm{~m}^{2} / \mathrm{s}-\right.$ 
$1133 \times 10^{-3} \mathrm{~m}^{2} / \mathrm{s}$ ). In addition, the potential recharge rate $R$ has been estimated at $200 \mathrm{~mm}$ per year

114 (Carn, 1990; Leray et al., 2012; Touchard, 1999). Following these constraints, each model has

115 been calibrated against the mean piezometric level measured at the pumping well (-5.5 masl)

116 in steady-state flow under pumping conditions (Leray et al., 2012) by slightly adjusting the

117 contact zone transmissivity previously estimated from long-term pumping tests (Le Borgne et

118 al., 2006). Uniform porosity has also been calibrated against the CFC-12 age (30 years \pm 1

119 year in 2009). Note that the overall volume of the system is about $1.5 \times 10^{9} \mathrm{~m}^{3}$ and the mean

120 residence time of the model - i.e. the first moment of the residence time distribution - is

121 around 13 years in ambient conditions and 50 years in pumping conditions. .

122 Our study has been carried out on about ten representative hydrogeological models differing

123 by their structure, their micaschists permeability and their porosity. The interest of

124 considering different models is to investigate the potential influence of the hydrogeological

125 structure on the apparent ages and their evolution. We discuss further in section 4 how this

126 sensitivity might be useful as an additional way to characterize the flow pattern. Among this

127 set of models, only two are used here to illustrate the methodology as they all lead to the same

128 conclusions. Table 1 synthesizes the parameters of the two chosen hydrogeological models.

\subsection{Flow model}

130 Transient flow conditions are induced by starting a pumping well. The transient pumping rate

$Q_{\mathrm{w}}(t)$ is a step function going from zero before the starting date $t_{s w i t c h}$, to a positive value $Q_{\mathrm{p}}$ :

$$
Q_{W}(t)= \begin{cases}0 & t \leq t_{\text {switch }} \\ Q_{p} & t>t_{\text {switch }}\end{cases}
$$


132 In the particular case of the site of Plœmeur, $Q_{\mathrm{p}}$ is set at $3.36 \times 10^{-2} \mathrm{~m}^{3} / \mathrm{s}$. Pumping started in

1331991 and the most part of the evolution of the piezometric levels occurred only in a few years

134 after the start of pumping. $t_{\text {switch }}$ has thus been set at 1994 . We solve the 3D diffusivity 135 equation for the hydraulic head $h(x, t)$ with free surface boundary conditions under a pseudo 136 transient flow approximation:

$$
\nabla \cdot(K(x) \nabla h(x, t))=0
$$

$$
\begin{gathered}
\left.K(\boldsymbol{x}) \nabla h(\boldsymbol{x}, t) \times \boldsymbol{n}=-R \quad \& \quad h(\boldsymbol{x}, t)=z(\boldsymbol{x}) \quad \begin{array}{c}
\text { where } h<z_{\text {ground }} \\
h=z_{\text {ground }} \\
\text { anywhere else }
\end{array}\right\} \text { on } \Gamma_{\mathrm{s}}(3) \\
\nabla h(\boldsymbol{x}) \times \boldsymbol{n}=0 \quad \text { on } \Gamma_{\text {west }} \text { and } \Gamma_{\text {east }} \\
h(\boldsymbol{x})=z_{\text {ground }}-z_{0} \text { on } \Gamma_{\text {north }} \text { and } \Gamma_{\text {south }} \\
\int K(\boldsymbol{x}) \nabla h(\boldsymbol{x}, t) \times \boldsymbol{n}_{\boldsymbol{w}} d \Gamma_{\mathrm{w}}=Q_{\mathrm{W}}(t) \text { sink term }
\end{gathered}
$$

137 where $K(\boldsymbol{x})$ is the hydraulic conductivity; $\boldsymbol{n}$ is the outgoing normal to the saturated domain; $R$

138 is the potential recharge rate; $z_{\text {ground }}$ is the ground surface elevation; $\Gamma_{\mathrm{s}}$ is the top of the 139 saturated domain; $\Gamma_{\text {west }}, \Gamma_{\text {east }}, \Gamma_{\text {north }}$ and $\Gamma_{\text {south }}$ are respectively the West, East, North and South

140 sides of the domain; $z_{0}$ is a reference height; $\boldsymbol{n}_{\mathrm{w}}$ is the ingoing normal to the well screen; $\Gamma_{\mathrm{w}}$ is

141 the well screen surface and $Q_{\mathrm{w}}(t)$ is the transient pumping rate defined in equation 1 and

142 located at $\boldsymbol{x}_{\mathrm{w}}$. The pseudo transient approximation intervenes in equation 6 and consists in

143 assuming that steady-state flow conditions are quickly established compared to the solute 
144 transport evolution. This is a reasonable approximation of transient flow conditions valid at

145 low specific storage and with the advantage of being less costly numerically. Practically, it

146 consists in ignoring the transition between the two steady-state velocity fields under ambient

147 and pumping conditions.

148 Equation 2 is solved in unconfined conditions since seepage conditions are a priori not

149 known. Unconfined conditions are satisfied through both conditions at the free surface

150 boundary of equation 3 . When the free surface level is below the ground surface level, the

151 effective recharge rate is equal to the potential recharge rate $R$; anywhere else, the free surface

152 level is set at $z_{\text {ground }}$ and the effective recharge rate continuously evolves from negative values

153 in the discharge zone to positive potential recharge rate $R$. The model has been built to

154 include the nearest watersheds both in ambient and pumping conditions in order to minimize

155 the potential effects of the boundary conditions. No-flow conditions applied on the West and

156 East boundaries (Equation 4, Figure 2) do not have any impact on the recharge areas captured

157 by the pumping zone located at depth in the pumping well. Imposed heads, set at depth $z_{0}(5$

158 meters below the ground surface level), are applied to the South and the North boundaries

159 without any significant influence on the system because of the almost impervious granites

160 (Equation 5, Figure 2).

Transport is considered only advective as the macro-scale dispersion from local dispersion and diffusion is assumed to have a much smaller effect compared to the macro-scale

164 dispersion induced by structural heterogeneity and sampling (LaBolle and Fogg, 2001).

165 Transport is modeled by the advection equation (Bear, 1991; de Marsily, 1986): 


$$
\begin{gathered}
\frac{\partial C(\boldsymbol{x}, t)}{\partial t}+\nabla \cdot\left(\frac{\boldsymbol{q}(\boldsymbol{x}, \boldsymbol{t})}{\theta} C(\boldsymbol{x}, t)\right)+\frac{Q_{\mathrm{W}}(t) C_{\mathrm{W}}(t)}{\theta}=0 \\
C(\boldsymbol{x}, t=0)=C_{0}(\boldsymbol{x}) \\
C(\boldsymbol{x}, t)=C_{1}(t) \text { on } \Gamma_{1}
\end{gathered}
$$

166 with $C(x, t)$ the solute concentration at the position $\boldsymbol{x}$ and at the time $t ; \theta$ the effective porosity; $Q_{\mathrm{w}}(t)$ the rate of the pumping well; $C_{\mathrm{w}}(t)$ the solute concentration at the pumping well; $C_{0}(\boldsymbol{x})$ the initial condition; $C_{1}(t)$ is the boundary condition on a first-type boundary $\left(\Gamma_{1}\right)$ - such as the tracer atmospheric concentration at the free surface boundary - and $\boldsymbol{q}(\boldsymbol{x}, t)$ the pseudo transient Darcy's flux derived from the head field $h(x, t)$ :

$$
q(x, t)=-K(x) \nabla h(x, t) .
$$

\subsection{Numerical methods}

172 The unconfined flow equations are solved using a computationally effective finite-volume

173 approach with a local adaptation scheme (Bresciani et al., 2011). The advection equation is

174 solved in backward-time that consists in reversing the flow field and adapting the boundary conditions (Neupauer and Wilson, 1999; Neupauer and Wilson, 2001; Neupauer and Wilson, 2002). To solve the transport equation, we use a Lagrangian random walk method well-suited to purely advective transport (de Dreuzy et al., 2007; Kinzelbach, 1988) and adapted to the unconfined conditions and to the backward-time resolution. We inject particles proportionally to flow (Kreft and Zuber, 1978) at the pumping well cell and tracked them to the aquifer free 
180

181

182

183

$$
C_{\mathrm{w}}=\int_{0}^{+\infty} C_{\mathrm{in}}\left(t_{w}-t\right) p(t) d t=\int_{-\infty}^{+\infty} C_{\text {in }}(t) p\left(t_{w}-t\right) d t .
$$

Note that, to highlight that the residence time distribution $p(t)$ is highly dependent on a given sampling date $t_{\mathrm{w}}$, we later use it as $p\left(t_{\mathrm{w}}-t\right)$ where $t_{\mathrm{w}}-t$ represents the date at which water recharged, rather than as a function of the residence time " $t$ " alone. Throughout the paper, $p\left(t_{\mathrm{w}}-t\right)$ is named recharge date distribution. The apparent age $A$ (Nir, 1964) of a tracer at the pumping well $\boldsymbol{x}_{\mathrm{w}}$ and at the sampling date $t_{\mathrm{w}}$ is then obtained from the difference between $t_{\mathrm{w}}$ and the date at which the concentration $C_{\mathrm{w}}$ is equal to the atmospheric concentration:

$$
A\left(t_{w}\right)=t_{w}-C_{\text {in }}^{-1}\left(C_{\mathrm{w}}\right)=t_{w}-C_{\text {in }}^{-1}\left(\int_{-\infty}^{t_{\mathrm{w}}} C_{\tilde{\mathrm{in}}}(t) p\left(t_{w}-t\right) d t\right)
$$

196 with $C_{\text {in }}^{-1}$ the reciprocal function of the atmospheric concentration. 
Equation 12 shows the two possible causes of the variation of age $A$ with the sampling date $t_{\mathrm{w}}$.

198 The first cause is the evolution of the recharge date distribution $p\left(t_{\mathrm{w}}-t\right)$ because of the modification of flow conditions that can be traced back to equation 1 through equations 2-11.

The shift from ambient to pumping conditions does not only change the flow magnitude but also the flow pattern, the recharge and discharge locations as well as the water mixing within the radius of action of the well (Bredehoeft, 2002). This first cause is solely linked to the flow conditions and does not depend on the tracer characteristics.

204 The second cause of the age variation directly comes from the tracer atmospheric concentration $C_{\text {in }}(t)$ through the convolution of equation 11. The non-linear temporal evolution of $C_{\mathrm{in}}(t)$ modifies the sampling of the recharge date distribution $p\left(t_{\mathrm{w}}-t\right)$. Monotonic and steep evolutions of $C_{\mathrm{in}}(t)$ characteristic of the $\mathrm{SF}_{6}$ and CFCs approximately between the 1970s and 1990s results in a large range of weights of the residence times in this period.

209 Flatter evolutions characteristic of the CFCs after the early 1990s give a higher but more equilibrated contribution of the shorter residence times. Depending on the sampling date $t_{\mathrm{w}}$,

211 this equilibrated contribution is more or less significant. This effect occurs both in transient 212 and steady-state flow conditions (Troldborg et al., 2008; Waugh et al., 2003; Zhang, 2004). 213 Even under steady-state flow conditions, the non-linear evolution of the atmospheric 214 concentration $C_{\text {in }}(t)$ lets the sampled concentration evolve. Under simpler terms, the evolution 215 of the sampled concentration does not only come from the evolution of the system but also 216 from the modification of the "observation device" $\left(C_{\text {in }}\right)$.

217 It should be noted that this second effect is irrelevant when mixing is minimal like within the 218 framework of the piston-flow model. In such cases, the residence time distribution resumes to 219 a Dirac and the dependency to the tracer atmospheric concentration vanishes in equation 12 220 because of the direct transformation of $C_{\mathrm{in}}$ by $C_{\mathrm{in}}{ }^{-1}$. This effect is, however, very relevant 
close to the aquifer discharge zones (springs, wells) where the mixing of flow paths is

222

223

224

225

226

maximal. The mixing of sampled flow lines enhances the importance of the non-linear evolution of $C_{\mathrm{in}}(t)$. The case studied here pertains more to this second situation, in which, finally, both the temporal evolutions of the recharge date distributions $p\left(t_{\mathrm{w}}-t\right)$ and the tracer atmospheric concentration $C_{\text {in }}(t)$ can modify the sampled concentration and the derived age $A\left(t_{\mathrm{w}}\right)$ (equation 12).

To analyze the temporal evolution of the apparent ages, we have determined them using equation 12 by convoluting the recharge date distributions $p\left(t_{\mathrm{w}}-t\right)$ obtained under the pseudo transient conditions with the CFC-11, CFC-12, CFC-113 and $\mathrm{SF}_{6}$ atmospheric concentrations at the evolving sampling dates $t_{w}^{i}$ from 1994 to 2009 (Table 2). These dates correspond to sampling 0 to 15 years after the change of flow conditions from ambient to pumping conditions occurring at $t_{\text {switch }}=1994$.

\section{Results}

This section first reports the temporal evolution of the apparent ages at the pumping well for the hydrogeological model numbered 1 of the site of Plœmeur described in section 1 and in Table 1. It then analyses the respective effects of the modification of the flow pattern and of the evolution of the tracer atmospheric concentration. The implication of the temporal eyolution of the apparent ages for models segregation is further discussed in section 4.1 by comparing the results of the models numbered 1 and numbered 2.

\subsection{Temporal evolution of apparent age}

Figure 3 shows the evolution of the apparent ages from CFC-11, CFC-12, CFC-113 and $\mathrm{SF}_{6}$ concentrations with the sampling date $t_{\mathrm{w}}$ ranging from 1994 (ambient conditions) to 2009 
243 (Table 2). At first sight, the apparent ages increase first sharply after the start of pumping and

244 then more smoothly whatever the tracer. We indeed expect that the modifications of flow are

245 maximal just after the start of the pumping and later decrease. Though similar, the apparent 246 ages derived from the CFCs and $\mathrm{SF}_{6}$ still exhibit some differences induced by the tracer 247 atmospheric concentration $C_{\mathrm{in}}(t)$. The temporal evolution is minimal for $\mathrm{SF}_{6}$ because of the 248 almost linear increase of its atmospheric concentration and maximal for the CFC-11 and 249 CFC-12 because of the strong and non-monotonic variations of their atmospheric concentration (IAEA, 2006). CFC-11 and CFC-12 display similar variations because of the similar shapes of their atmospheric concentration chronicles.

The increase of the apparent ages in the models considered here is somehow counterintuitive. Indeed, in the exponential model (Haitjema, 1995), the residence time distribution is 254 independent of the pumping rate. Besides, in the piston-flow model, as said in section 2.5, apparent ages remain constant whatever the sampling dates due to minimal mixing. When starting a pumping in those conditions, one would expect an increase of velocity that would directly reduce the residence time and then the apparent ages. In the more complex system modeled here, pumping has a nontrivial effect on the apparent ages. Further insight is given 259 by the analysis of the recharge date distribution $p\left(t_{\mathrm{w}}-t\right)$ and its temporal evolution. Figure 4

260 shows the recharge date distribution sampled at three different dates : (a) at $t_{w}^{1}=1994$ under

262 started and (c) at $t_{w}^{3}=1995$ one year after the pumping started. At later dates $\left(t_{\mathrm{w}} \geq 1995\right)$, 
264 For $1994 \leq t_{w} \leq 1995$, the system is strongly transient (Figure $4 \mathrm{a}$ and $b$ ). The start of

265 pumping induces a modification of the recharge date distribution from a narrow piston-like

266 distribution at ambient conditions $\left(t_{w}^{1}\right)$ (Figure $4 \mathrm{a}$ ) to a much broader, more exponential-like,

267 later (Figure 4c). Intermediary distribution shapes occur in the first pumping year (Figure 4b).

268 The broadening of the distribution comes from the shift of status of the sampling zone. Under 269 ambient flow conditions, it is a standard zone within the aquifer broken through by just a few

270 flow lines. The different tracers then lead to very close ages (Figure 3). Under pumping 271 conditions, it becomes the major discharge zone of the aquifer focusing a dense net of flow 272 lines that initially discharged in much larger areas such as wetlands (Figure 2) and apparent 273 ages from the different tracers spread out. For $t_{w} \geq 1994.1$, the recharge date distribution 274 broadens including both shorter and larger residence times than the ambient distribution. In 275 the case of the Plœmeur site, shorter residence times eventually control the apparent ages. 276 This is also consistent with the increase of the mean effective recharge rate and the induced 277 circulation speed up (from $160 \mathrm{~mm}$ /year in ambient conditions to 200mm/year in pumping 278 conditions). As previously noted, the distributions sampled in 1995 and later are almost 279 identical. Thus, for $t_{w} \geq 1995$, sampled concentrations are likely to be more influenced by the temporal evolution of the tracer atmospheric concentrations $C_{\text {in }}(t)$ and less by the 281 evolution of the recharge date distribution.

3.2. Effect of the temporal evolution of the recharge date distribution 
285 To assess the role of the temporal evolution of the recharge date distribution $\left(p\left(t_{\mathrm{w}}-t\right)\right.$ in 286 equation 12), we filter out the evolution of the tracer atmospheric concentration $\left(C_{\text {in }}(t)\right.$ in 287 equation 12). To this end, we translate the distributions $p_{i}\left(t_{w}^{i}-t\right)$ (Table 2) to the same 288 sampling date $t_{w}^{t}$, the exponent " $t$ " standing for translated. The recharge date distributions $p_{i}\left(t_{w}^{i}-t\right)$ are shifted along the date axis by a translation of $t_{w}^{t}-t_{w}^{i}$ without any modification of their shape. The shifted distributions are noted $p_{i}\left(t_{w}^{t}-t\right)$ :

$$
p_{i}\left(t_{w}^{t}-t\right)=p_{i}(\underbrace{t_{w}^{i}-t}_{\text {recharge time }}+\underbrace{t_{w}^{t}-t_{w}^{i}}_{\text {translation }}) .
$$

291 This is illustrated on Figure 5 for the three recharge date distributions of Figure 4 translated to $t_{w}^{t}=2009$. The apparent age determination is modified accordingly:

$$
A\left(t_{w}^{\mathrm{t}}\right)=t_{w}^{t}-C_{\mathrm{in}}^{-1}\left(\int_{-\infty}^{t_{w}^{t}} C_{\mathrm{in}}(t) p_{\mathrm{i}}\left(t_{w}^{t}-t\right) d t\right)
$$

293 Equation 14 replaces equation 12 and filters out most of the effect of the tracer atmospheric 294 concentration $C_{\text {in }}(t)$ to highlight that of the evolution of the flow pattern. The apparent ages 
are noted $A\left(t_{w}^{t}\right)$ recalling that they are obtained after the translation of the recharge date

distributions.

\subsubsection{Results}

Figure 6 compares the apparent ages obtained with the various recharge date distributions translated to the same sampling date $t_{w}^{6}=2009$ for the model numbered 1 . The apparent ages are derived from equation 14 and are noted $A\left(t_{w}^{6}\right)$. As for the apparent ages from equation 12 , the apparent ages $A\left(t_{w}^{t}\right)$ from equation 14 are first almost identical for the four tracers because of the piston-like shape of the ambient distribution. Because of the broadening of the recharge date distributions after the start of pumping, they diverge from each other to finally reach fixed values spreading over almost 15 years (four last points of Figure 6). The apparent ages $A\left(t_{w}^{t}\right)$ from the distribution initially sampled at $t_{w}^{i}=1994.1$ (i.e. one month after the pumping started) constitute an intermediate case. Indeed, unlike the ages from the ambient distribution, they significantly diverge for the four tracers. However, their spreading is not as broad as for the distributions sampled at later dates $\left(t_{w}^{i} \geq 1995\right)$. We will discuss in section 4.1 the interest of these differences for model segregation. We have checked that the conclusions were the same for the other sampling dates of Table 2.

3.3. Effect of the temporal evolution of the atmospheric concentration 
314 To assess the influence of the tracer atmospheric concentration $C_{\text {in }}(t)$ independently of the

315 flow pattern modifications, we compute the apparent ages at six translated sampling dates $t_{w}^{t}$

316 (Table 2) for a fixed recharge date distribution. Figure 7 illustrates this analysis for the pseudo

317 transient distribution initially sampled at $t_{w}^{3}=1995$ and translated to 2004 and 2009. This

318 transformation should not be confounded with the previous one in which we studied the

319 influence of the recharge date distributions at fixed atmospheric concentration $C_{\mathrm{in}}(t)$.

\subsubsection{Results}

321 Figure 8a, b and c display the results for the three distributions of Figure $4 \mathrm{a}, \mathrm{b}$ and $\mathrm{c}$. For the

322 ambient distribution (initially arising at $t_{w}^{i}=t_{w}^{1}=1994$ ), the evolution of $A\left(t_{w}^{t}\right)$ with $t_{w}^{t}$

323 remains very small (Figure 8a) because of the restricted dispersion of the recharge date

324 distribution (blue curve of Figure 4a). It would be strictly equal to zero for a pure piston-flow

325 model. For broader recharge date distributions corresponding to the pseudo transient case

326 sampled at $t_{w}^{i}=t_{w}^{3}=1995$ (Figure 8c), the apparent ages strongly evolve with $t_{w}^{t}$. The

327 weighting of the recharge date distribution progressively evolves with date and yields

328 different ages consistently with Figure 3. Similar results have been found for the pseudo

329 transient distributions sampled after $t_{w}^{3}(\geq 1995)$. For the distribution initially sampled one

330 month after the pumping started (at $\left.t_{w}^{i}=1994.1\right)$, the apparent age variation with $t_{w}^{t}$ is still

331 significant though less important than the age variation from the posterior distributions. 
332

333

In conclusion, the two previous analyses highlight the respective effects of the recharge date distribution (3.2) and of the tracer atmospheric concentration (3.3). They show two welldifferentiated regimes of apparent age evolution. The first regime occurs within the first few months after starting the pumping. Note that it is fast in comparison to the mean residence time (50 years). The recharge date distribution shifts from a restricted distribution to an extended one with major consequences on apparent ages. Relatively parallel flow lines under ambient conditions become convergent under pumping inducing the broadening of the recharge date distribution. By comparison, on these short durations (some months), the evolution of the atmospheric concentration has a negligible effect. The second regime occurs after the first year of pumping and lasts for longer period of times. The recharge date distribution marginally changes without any marked effect on the apparent ages. The dominant source of age variation is the non-linear evolution of the tracer atmospheric concentration. This reveals that apparent ages can significantly evolve even if fluid flows and transport are at steady-state. If the second regime is smoother than the first one, it still leads to significant variation of ages (Figure 3).

\section{Discussion}

We first discuss the potential interest of the two successive evolutions of apparent ages, i.e. a first phase dominated by the transient flow pattern and a second one by the transient atmospheric concentration for flow pattern characterization and models segregation. We secondly compare these modeling results to the available data on the site of Plœmeur.

\subsection{Information contained in the temporal evolution of apparent ages}


354 The temporal evolution of apparent ages contains information on the hydrogeological system,

355 in addition to information contained in the tracer concentrations analyzed at a single time.

356 Yet, information is largely different between the two evolutions identified in sections 3.2 and

357 3.3. The first evolution is the rapid shift when starting pumping from a restricted recharge

358 date distribution to an extended one. The restricted recharge date distribution can be typically

359 fitted by an inverse Gaussian model characterizing mainly the length of the flow paths from

360 the recharge zone divided by the recharge rate (Ginn et al., 2009; Woolfenden and Ginn,

361 2009). The broader recharge date distribution characterizes more globally the aquifer volume

362 and the overall recharge rate (Leray et al., 2012), so does typically the exponential model

363 (Haitjema, 1995). Therefore, almost independent and useful pieces of information, such as a

364 characteristic length vs. a volume, can be obtained using the same well before and after the

365 start of pumping. Using equation 12 as an illustration, it comes down to use the temporal

366 evolution of apparent ages to estimate the transient controlling parameters of the function

$367 p\left(t_{\mathrm{w}}-t\right)$.

368 Figure 9 compares the temporal evolution of the CFC-12 age for the models numbered 1 and

369 numbered 2 (Table 1) at sampling dates ranging from 1994 to 2009 (Table 2). It shows that

370 the two models give distinct apparent ages before 1995 i.e. when the recharge date 371 distribution is transient. Later, once the recharge date distribution is broad and reaches a 372 steady-state, and because the two models have been calibrated on CFC-12 age in 2009, the

373 apparent ages are identical for both models. Differences only occur at short term after the

374 pumping started and result from different transient evolutions of the residence time

375 distribution. This underlines the interest of a continuous sampling of environmental tracer

376 concentrations, particularly at the early times of pumping, to characterize the transient

377 behavior of the system. In that case, apparent age time series can be used as an additional tool 
to segregate hydrogeological models. Using equation 12 as an illustration, it comes down to use the temporal signal in apparent ages to segregate two functions $p\left(t_{\mathrm{w}}-t\right)$ that exhibit distinct transient behaviors.

\subsection{Comparison to field observations on the site of Plœmeur} Apparent ages obtained from CFC-11, CFC-12, CFC-113 and $\mathrm{SF}_{6}$ data have been determined on the site of Plœmeur since 2006 and recorded in the Plœmeur site database (Ayraud et al., 2008; de Dreuzy et al., 2006). In the pumping well, data are available in 2006 and 2009. CFC12 age increases from 27.5 in 2006 to 30 years in 2009 and CFC-113 age decreases from 28.5 to 26.5 years. $\mathrm{CFC}-11$ ages are close to 45 years and remain constant with time. Still, they should be very close to CFC-12 apparent ages because of the similar normalized atmospheric concentrations of the two tracers. As already reported in Leray et al. (2012), degradation of CFC-11 under anaerobic conditions may explain these differences (Cook and Solomon, 1995). $\mathrm{SF}_{6}$ apparent ages are less than 10 years. Such discrepancies cannot be explained by hydrodynamic mixing alone even at the pumping well (Leray et al., 2012) but are rather coming some geogenic production from the neighboring granites (Busenberg and Plummer, 2000; Koh et al., 2007).

The results of the models in section 3 suggest that with negligible temporal change of the recharge date distribution, the apparent age should continuously increase whatever the tracer and within the date interval 2000-2010. The CFC-12 age increase at the Plœmeur site is similar in terms of magnitude to that of the models. CFC-12 data thus suggest that the tracer age evolution in that discharge area mainly comes from the temporal evolution of the atmospheric concentration weighting and that the flow pattern and the resulting recharge date distribution in the pumping zone are in turn not expected to vary significantly after 2006. 
Still, CFC-113 exhibits an opposite age variation in comparison with CFC-12. Considering

402

403 the age uncertainty due to analytical and sampling errors (Leray et al., 2012), the acquisition of additional concentration data over the next few years would help to confirm the age trends and eventually conclude about the flow pattern stabilization.

Earlier flow conditions, and particularly initial ones i.e. just before the pumping started, are more difficult to constrain on the site of Plœmeur because of the lack of environmental tracers monitoring before 2006. Contrary to $\mathrm{CFCs}$ and $\mathrm{SF}_{6}$ data, chloride and nitrate concentrations have been monitored on a longer date range starting at 1991. Because of reactivity processes and their evolution with time, the nitrate concentration chronicle can only give partial information on the flow pattern and on mixing processes. However, its non-negligible initial concentration (roughly $15 \mathrm{mg} / \mathrm{l}$ ) before the start of pumping indicates short residence times consistent with the local recharge area and the short flow paths obtained in the models. Chloride has the advantage of being conservative and being characteristic of deeper waters and thus a good indicator of the flow pattern and its evolution. Figure 10 represents the temporal evolution of chloride concentration at the pumping well. It displays a sharp increase during the first two years of pumping $\left(1^{\text {st }}\right.$ phase of Figure 10$)$, a very slight increase for the next ten years $\left(2^{\text {nd }}\right.$ phase of Figure 10$)$ and finally stabilizes after $2005\left(3^{\text {rd }}\right.$ phase of Figure 10). The first phase is consistent with the previous modeling result of a quick transition from the piston-like recharge date distribution to the more extended one. The short duration of the first phase is consistent with the fast temporal evolution of the recharge area (Figure 11). Before pumping, the recharge area is a small zone upstream of the well (blue line). It quickly expands to a much larger area around the well only after one year of pumping (green line). Actually, the pumping well collects water that naturally discharged in wetlands next to it and transforms a wide discharge zone to a point-like one. 
425 The $2^{\text {nd }}$ phase corresponds to a slight increase of the chloride concentration (Figure 10). This

426 increase does not come from the changes of the recharge area induced by the evolution of the

427 flow pattern, in this case marginal (from orange to purple curves in Figure 11). It more likely

428 comes from the modification of the deep water fraction coming from the main aquifer-i.e.

429 the contact zone - that dips quasi-vertically at about 1,500m from the pumping well (Figure

430 11, (Ruelleu et al., 2010)). Its evolution only affects recharge dates earlier than 1940 and

431 cannot consequently be detected by atmospheric gases. Finally, the stabilization of the

432 chloride concentration $\left(3^{\text {rd }}\right.$ phase of Figure 10) agrees with the apparition of a new steady-

433 state regime.

\section{Conclusion}

We have analyzed the temporal evolution of apparent ages in a complex aquifer under pumping based on CFCs and $\mathrm{SF}_{6}$ concentrations measured at the pumping well. The evolution of apparent ages at the pumping well with time can come from (1) the transient nature of flow conditions and (2) the transient evolution of the tracer atmospheric concentrations. To identify the respective role of these two sources, we proposed two successive analyses of the residence

440 time distributions: (1) convolution at the same sampling date (i.e. with the same atmospheric 441 concentration chronicle) of residence time distributions initially arising at different dates to 442 assess the effect of the distributions, (2) convolution of one residence time distribution at 443 various sampling dates (i.e. with various atmospheric concentration chronicles) to assess the 444 effect of the atmospheric concentration.

445 We identify two well-differentiated phases in the evolution of apparent ages. Apparent ages 446 first evolve because of the pumping-induced modifications of flows. At this stage, the temporal evolution of apparent ages is distinct between two hydrogeological models and may 
448 be advantageously used to segregate them using for instance a classical least square 449 comparison procedure of data with modeling results. The transient measure of the tracer 450 concentrations contain some additional information and slightly compensate for the small 451 number of available tracers. After one year of pumping, residence time distributions hardly 452 evolve and apparent ages become solely modified by the transient evolution of the 453 atmospheric concentrations. Apparent ages still significantly evolve but do not contain any 454 additional information on the flow patterns beyond those contained in the steady-state data.

\section{Acknowledgments}

456 Funding was provided by the French National Research Agency ANR through the H2MNO4 457 project for the development of parallel simulation methods (ANR-11-MN). Research and 458 monitoring on the site of Plœmeur is funded by the Environmental research Observatory $\mathrm{H}+$ 459 (Network of hydrogeological sites) and by the European Interreg IV project Climawat. J.-R. 460 de Dreuzy acknowledges the European Union for its additional funding through the IEF 461 Marie-Curie fellowship (PIEF-GA-2009-251710). The authors acknowledge Arash 462 Massoudieh and an anonymous reviewer for their fruitful reviews. 
466

467

468

469

470

471

472

473

474

475

476

477

478

479

480

481

482

483

484

485

486

487

488

489

490

491

492

493

494

495

496

497

498

499

500

501

502

503

504

Ayraud, V., 2005. Détermination du temps de résidence des eaux souterraines: application au transfert d'azote dans les aquifères fracturés hétérogènes. Ph.D Thesis, Université de Rennes 1, Rennes, $312 \mathrm{pp}$.

Ayraud, V., Aquilina, L., Labasque, T., Pauwels, H., Molenat, J., Pierson-Wickmann, A.-C., Durand, V., Bour, O., Tarits, C., Le Corre, P., Fourre, E., Merot, P., Davy, P., 2008. Compartmentalization of physical and chemical properties in hard-rock aquifers deduced from chemical and groundwater age analyses. Applied geochemistry, 23(9): 2686-2707. doi:10.1016/j.apgeochem.2008.06.001.

Bear, J., 1991. Modelling and applications of transport phenomena in porous media. Theory and applications of transport in porous media. Kluwer Academic Publishers, Dordrecht.

Bredehoeft, J.D., 2002. The Water Budget Myth Revisited: Why Hydrologists Model. Groundwater, 40(4): 340-345.

Bresciani, E., Davy, P., de Dreuzy, J.-R., 2011. A finite volume approach with local adaptation scheme for the simulation of free surface flow in porous media. International Journal For Numerical and Analytical Methods in Geomechanics, 36(13): 1574-1591. doi:10.1002/nag.1065.

Busenberg, E., Plummer, L.N., 2000. Dating young groundwater with sulfur hexafluoride: Natural and anthropogenic sources of sulfur hexafluoride. Water Resour. Res., 36(10): 3011-3030. doi:10.1029/2000WR900151.

Carn, A., 1990. Mise en valeur des ressources en eau souterraine du socle breton.Département du Morbihan (35) - R31724 BRE 4S/90, BRGM, Rennes.

Castro, M.C., Goblet, P., Ledoux, E., Violette, S., de Marsily, G., 1998. Noble gases as natural tracers of water circulation in the Paris Basin, 2. Calibration of a groundwater flow model using noble gas isotope data. Water Resour. Res., 34(10): 2467-2483.

Cook, P.G., Love, A.J., Robinson, N.I., Simmons, C.T., 2005. Groundwater ages in fractured rock aquifers. Journal of Hydrology, 308(1-4): 284-301. doi:10.1016/j.jhydrol.2004.11.005.

Cook, P.G., Solomon, D.K., 1995. Transport of atmospheric trace gases to the water table Implications for groundwater dating with chlorofluorocarbons and krypton-85. Water Resour. Res., 31(2): 263-270. doi:10.1029/94WR02232.

de Dreuzy, J.-R., Beaudoin, A., Erhel, J., 2007. Asymptotic dispersion in 2D heterogeneous porous media determined by parallel numerical simulations Water Resour. Res., 43(10). doi:10.1029/2006WR005394.

de Dreuzy, J.-R., Bodin, J., Le Grand, H., Davy, P., Boulanger, D., Battais, A., Bour, O., Gouze, P., Porel, G., 2006. General database for ground water site information. Groundwater, 44(5): 743-748. doi:0.1111/j.1745-6584.2006.00220.x.

de Marsily, G., 1986. Quantitative hydrogeology: Groundwater Hydrology for Engineers. Academic Press, New-York, 440 pp. 
Erhel, J., de Dreuzy, J.-R., Bresciani, E., 2008. Multi-parametric intensive stochastic simulations for hydrogeology on a computational grid. In: Tromeur-Dervout, D., Brenner, G., Emerson, D., Erhel, J. (Eds.), Parallel Computational Fluid Dynamics. Springer, Lecture Notes in Computational Science and Engineering, pp. 389-397.

Erhel, J., de Dreuzy, J.R., Beaudoin, A., Bresciani, E., Tromeur-Dervout, D., 2009. A parallel scientific software for heterogeneous hydrogeoloy. In: Tuncer, I.H., Gulcat, U., Emerson, D.R., Matsuno, K. (Eds.), Parallel Computational Fluid Dynamics 2007. Lecture Notes in Computational Science and Engineering. Springer, pp. 39-48.

Frind, E.O., Muhammad, D.S., Molson, J.W., 2005. Delineation of Three-Diemnsional Well Capture Zones for Complex Multi-Aquifer Systems. Groundwater, 40(6). doi:10.1111/j.1745-6584.2002.tb02545.x.

Ginn, T.R., Haeri, H., Massoudieh, A., Foglia, L., 2009. Notes on Groundwater Age in Forward and Inverse Modeling. Transport in Porous Media, 79(1): 117-134. doi:10.1007/s11242-009-9406-1.

Haitjema, H.M., 1995. On the residence time distribution in idealized groundwatesheds. J. Hydrol., 172(1-4): 127-146. doi:10.1016/0022-1694(95)02732-5.

IAEA, 2006. Use of chlorofluorocarbons in hydrology : a guidebook. International Atomic Energy Agency, Vienna, 277 pp.

Kinzelbach, W., 1988. The random-walk method in pollutant transport simulation. In: Custodio, E., Gurgui, A., Lobo Ferreira, J.P. (Eds.), Groundwater flow and quality modelling. NATO ASI. Dordrecht, New York, pp. 227-246.

Koh, D.-C., Plummer, L.N., Busenberg, E., Kim, Y.-J., 2007. Evidence for terrigenic $\mathrm{SF}_{6}$ in groundwater from basaltic aquifers, Jeju Island, Korea : Implications for groundwater dating. J. Hydrol., 339(1-2): 93-104. doi:10.1016/j.jhydrol.2007.03.011.

Kreft, A., Zuber, A., 1978. On the physical meaning of the dispersion equation and its solution for different initial and boundary conditions. Chemical Engineering Science, 33(11): 1471-1480. doi:10.1016/0009-2509(78)85196-3.

LaBolle, E.M., Fogg, G.E., 2001. Role of molecular diffusion in contaminant migration and recovery in an alluvial aquifer system. Transp. Porous Media, 42(1-2): 155-179. doi:10.1023/A:1006772716244.

Le Borgne, T., Bour, O., de Dreuzy, J.-R., Davy, P., Touchard, F., 2004. Equivalent mean flow models for fractured aquifers: Insights from a pumping tests scaling interpretation. Water Resour. Res., 40(3). doi:10.1029/2003WR002436.

Le Borgne, T., Bour, O., Paillet, J.-L., Caudal, J.-P., 2006. Assessment of preferential flow path connectivity, and hydraulic properties at single-borehole and cross-borehole scales in a fractured aquifer. J. Hydrol., 328(1-2): 347-359.

Leray, S., de Dreuzy, J.R., Bour, O., Bresciani, E., 2013. Numerical modeling of the productivity of vertical to shallowly dipping fractured zones in crystalline rocks. J. Hydrol., 481: 64-75.

Leray, S., de Dreuzy, J.R., Bour, O., Labasque, T., Aquilina, L., 2012. Contribution of age data to the characterization of complex aquifers. J. Hydrol., 464-465: 54-68. doi:10.1016/j.jhydrol.2012.06.052. 
Long, A.J., Putnam, L.D., 2009. Age-distribution estimation for karst groundwater : Issues of parameterization and complexity in inverse modeling by convolution. J. Hydrol., 376: 579-588.

Maloszewski, P., Zuber, A., 1982. Determining the turnover time of groundwater systems with the aid of environmental tracers, 1. Models and their applicability. J. Hydrol., 57(3-4): 207-231.

McMahon, P.B., Carney, C.P., Poeter, E.P., Peterson, S.M., 2010. Use of geochemical, isotopic, and age tracer data to develop models of groundwater flow for the purpose of water management, northern High Plains aquifer, USA. Applied geochemistry, 25: 910-922. doi:10.1016/j.apgeochem.20120.04.001.

Neupauer, R.M., Wilson, J.L., 1999. Adjoint method for obtaining backward-in-time location and travel time probabilities of a conservative groundwater contaminant. Water Resour. Res., 35(11): 3389-3398. doi:10.1029/1999WR900190.

Neupauer, R.M., Wilson, J.L., 2001. Adjoint-derived location and travel time probabilities for a multidimensional groundwater system. Water Resour. Res., 37(6): 1657-1668. doi:10.1029/2000WR900388.

Neupauer, R.M., Wilson, J.L., 2002. Backward probabilistic model of groundwater contamination in non-uniform and transient flow. Advances in Water Resources, 25(7): 733-746.

Nir, A., 1964. On the interpretation of tritium 'Age' measurements of groundwater. journal of Geophysical Research, 69(1): 2589-2595.

Ruelleu, S., Moreau, F., Bour, O., Gapais, D., Martelet, G., 2010. Impact of gently dipping discontinuities on basement aquifer recharge: An example from Plœmeur (Brittany, France). Journal of Applied Geophysics, 70(2): 161-168. doi:10.1016/j.jappgeo.2009.12.007.

Sanford, W.E., Plummer, L.N., McAda, D.P., Bexfield, L.M., Anderholm, S.K., 2004. Hydrochemical tracers in the middle Rio Grande Basin, USA: 2. Calibration of a groundwater-flow model. Hydrogeol. J., 12(4): 389-407. doi:10.1007/s10040-0040326-4.

Schwartz, F.W., Sudicky, E.A., McLaren, R.G., Park, Y.-J., Huber, M., Apted, M., 2010. Ambiguous hydraulic heads and ${ }^{14} \mathrm{C}$ activities in transient regional flow. Groundwater, 48(3): 366-379.

Sophocleous, M., 2005. Groundwater recharge and sustainibility in the high Plains aquifer in Kansas, USA. Hydrogeol. J., 13: 351-365. doi:10.1007/s 10040-004-0385-6.

Stichler, W., Maloszewski, P., Bertleff, B., Watzel, R., 2008. Use of environmental isotopes to define the capture zone of a drinking water supply situated near a dredge lake. J. Hydrol., 362: 220-233. doi:10.1016/j.jhydrol.2008.08.024.

Touchard, F., 1999. Caractérisation hydrogéologique d'un aquifère en socle fracturé : Site de Plœmeur (Morbihan). PhD Thesis, University of Rennes 1, France, 343 pp.

Troldborg, L., Jensen, K.H., Engesgaard, P., Refsgaard, J.C., Hinsby, K., 2008. Using environmental tracers in modeling flow in a complex shallow aquifer system. J. Hydrol. Eng., 13(11): 1037-1048. doi:10.1061/(asce)1084-0699(2008)13:11(1037). 
603

604

Waugh, D.W., Hall, T.M., Haine, T.W.N., 2003. Relationships among tracer ages. Journal of Geophysical Research, 108(C5): 3138. doi:10.1029/2002JC001325.

Woolfenden, L.R., Ginn, T.R., 2009. Modeled ground water age distributions. Groundwater, 47(4): 547-557.

Zhang, Y., 2004. Numerical simulations of dating young groundwater with multiple atmospheric tracers : CFC-11, CFC-12, $\mathrm{SF}_{6},{ }^{3} \mathrm{H} /{ }^{3} \mathrm{He}$ and ${ }^{85} \mathrm{Kr}$. In: Miller, C.T., Farthing, M.W., Gray, W.G., Pinder, G.F. (Eds.), 15th International Conference on Computational Methods in Water Resources. Developments in Water Science. Elsevier Science BV, Chapel Hill, NC, pp. 1367-1378.

Zinn, B.A., Konikow, L.F., 2007. Potential effects of regional pumpage on groundwater age distribution. Water Resour. Res., 43(6). doi:10.1029/2006WR004865.

Zuber, A., Rozanski, K., Kania, J., Purtschert, R., 2011. On some methodological problems in the use of environmental tracers to estimate hydrogeologic parameters and to calibrate flow and transport models. Hydrogeol. J., 19: 53-69. 
605 Tables

606 Table 1: Parameters of the two hydrogeological models of the site of Plœmeur used in this

607 study with their reference work. $H_{\mathrm{TOT}}$ represents the mean thickness of the aquifer system 608 composed of the micaschists and of the contact zone (Figure 1). The two models have been 609 calibrated on the piezometric level at the pumping well and on CFC-12 apparent age at the 610 pumping well.

611 Table 2 : Sampling dates $\boldsymbol{t}_{\mathbf{w}}^{\mathbf{i}}$ where the apparent ages are determined.

612 
614 Figure 1:3D diagram of the hydrogeological conceptual model composed of the contact zone,

615 the North $20^{\circ}$ normal fault, the micaschists and the two granites. The North $20^{\circ}$ normal fault

616 is underlined by black stripes. The red triangle locates the sampled pumping well. $H(x)$

617 represents the thickness of the aquifer system composed of the micaschists and the contact

618 zone. Its mean, noted $H_{\mathrm{TOT}}$, is taken as a proxy for the characterization of its structure. As a

619 convention, all positions are given in meters and vertical positions are negative below the sea

620 level and positive above. Adapted from Leray et al. (2012).

621 Figure 2: Boundary conditions applied to the model i.e. no flow on the East and the West 622 boundaries (black lines) and head imposed on the North and South boundaries (red lines). The 623 limits with the impervious granites are represented by black dashed lines. Discharge zones in 624 ambient conditions (green) are partly dried with starting the pumping. Specifically, the 625 wetland in the pumping zone entirely disappears. Figure 3: Apparent ages derived from CFCs 626 and $\mathrm{SF}_{6}$ concentrations as functions of the sampling date $t_{\mathrm{w}}$ for the model numbered 1 (Table $627 \quad 1)$.

628 Figure 4: Recharge date distributions $p\left(t_{\mathrm{w}}-t\right)$ of the model numbered 1 (solid curves, left 629 axis) superimposed on CFC-12 atmospheric concentration $C_{\text {in }}(t)$ (grey dashed line, right axis).

630 Recharge date distributions are sampled at: a) $t_{w}^{1}$ (1994 - ambient flow, blue curve), b) $t_{w}^{2}$

631 (1994.1, wine curve), and c) $t_{w}^{3}$ (1995, green curve). Superposition of the curves shows the 632 sampling of the tracer atmospheric concentration performed by the recharge date 633 distributions. 
634 Figure 5: CFC-12 atmospheric concentration $C_{\text {in }}(t)$ (grey dashes) superimposed on some

635 translated distributions $p_{i}\left(t_{\mathrm{w}}^{\mathrm{t}}-t\right)$ to the sampling date $t_{\mathrm{w}}^{\mathrm{t}}=2009$ for the model numbered 1

636 (Table 1). The translated distributions are the ambient distribution (initially sampled at

$637 t_{w}^{1}=1994$, blue curve) and two pseudo transient distributions initially sampled at

$638 t_{\mathrm{w}}^{2}=1994.1$ (wine curve) and at $t_{\mathrm{w}}^{3}=1995$ (green curve). Note that the ordinate axis has

639 been broken between 0.05 and 0.19 to display the peak of the ambient distribution.

640 Figure 6: Apparent ages derived from $\mathrm{CFCs}$ and $\mathrm{SF}_{6}$ concentrations for the translated

641 recharge date distributions $p_{i}\left(t_{\mathrm{w}}^{6}-t\right)$ with $i$ from 1 to 6 for the model numbered 1 (Table 2).

$642 p_{1}$ corresponds to the blue curve of the Figure 5 (translated ambient distribution), $p_{2}$ to the

643 wine curve of the Figure 5 and $p_{3}$ to the green curve of the Figure 5.

644 Figure 7: Recharge date distribution $p_{3}$ at its initial sampling date $t_{w}^{3}=1995$ (green solid

645 curve) and translated to $t_{w}^{t}=2004$ (green dash dots) and translated to $t_{w}^{t}=2009$ (green

646 short dashes) for the model numbered 1 (left axis) superimposed on the CFC-12 atmospheric

647 concentration $C_{\text {in }}(t)$ (grey dashed line, right axis)

648 Figure 8: Apparent ages derived from $\mathrm{CFCs}$ and $\mathrm{SF}_{6}$ concentrations as functions of the

649 translated sampling date $t_{w}^{t}$ for the model numbered 1. Apparent ages are obtained for (a) the

650 translated ambient distribution $p_{1}\left(t_{\mathrm{ww}}^{\mathrm{t}}-t\right.$ ) (blue curve of Figure 4a), (b) the translated 
pseudo transient distribution $p_{2}\left(t_{\mathrm{w}}^{\mathrm{t}}-t\right)$ (wine curve of Figure $4 \mathrm{~b}$ ) and (c) the translated

652 pseudo transient distribution $p_{3}\left(t_{\mathrm{w}}^{\mathrm{t}}-t\right)$ (green curve of Figure $4 \mathrm{c}$ ).

653 Figure 9: CFC-12 ages of the model numbered 2 (blue crosses) as a function of CFC-12 ages

654 of the model numbered 1 (Table 1). CFC-12 ages are computed at the pumping well and at 655 sampling dates between 1994 and 2009 (Table 2). Labels next to the crosses stand for the 656 corresponding sampling dates. We recall that the two models have both been calibrated on the 657 CFC-12 age in 2009. Results for the tracers CFC-11, CFC-113 and SF $_{6}$ are similar and thus 658 are not shown.

659 Figure 10: Chloride concentration as a function of the sampling date $t_{\mathrm{w}}$ measured at the 660 pumping well of the site of Plœmeur (updated from Ayraud (2005)). The first phase consists 661 in a sharp and fast increase of the chloride concentration, the second phase in a slight increase 662 of the chloride concentration and the third phase in the stabilization of the chloride 663 concentration.

664 Figure 11: Surface origin of the CFCs and SF6 (corresponding to recharge dates posterior to 665 1940) for the model numbered 1 (Table 1) under pseudo transient conditions sampled at $t_{w}^{1}$

666 (1994 - ambient flow, blue line), at $t_{w}^{2}$ (1994.1, wine line), at $t_{w}^{3}$ (1995, green line), at $t_{w}^{4}$

667 (1999, orange line), at $t_{w}^{5}\left(2004\right.$, red line) and at $t_{w}^{6}$ (2009, purple wine). 


\begin{tabular}{|c|c|c|c|}
\hline & \multicolumn{2}{|l|}{ Values } & References \\
\hline \multicolumn{4}{|l|}{ Common parameters } \\
\hline Potential recharge rate $R(\mathrm{~mm} /$ year $)$ & & 200 & (Carn, 1990; Touchard, 1999) \\
\hline Granites conductivity $K_{\mathrm{G}}(\mathrm{m} / \mathrm{s})$ & & $10^{-11}$ & \\
\hline \multicolumn{4}{|l|}{ Specific parameters for selected models } \\
\hline & Model n ${ }^{\circ} 1$ & Model $n^{\circ} 2$ & \\
\hline $\begin{array}{l}\text { Mean thickness } H_{\text {ТОТ }}(\mathrm{m})-\text { structure } \\
\text { name }\end{array}$ & 180 - shallow & $280-$ deep & (Ruelleu et al., 2010) \\
\hline Micaschists permeability $K_{\mathrm{MS}}(\mathrm{m} / \mathrm{s})$ & $10^{-6}$ & $5 \times 10^{-6}$ & (Leray et al., 2012) \\
\hline Contact zone transmissivity $T_{\mathrm{CZ}}\left(\mathrm{x} 10^{-3} \mathrm{~m}^{2} / \mathrm{s}\right)$ & 2.27 & 2.2 & $\begin{array}{l}\text { (Le Borgne et al., 2004; Le Borgne et al., } \\
\text { 2006) }\end{array}$ \\
\hline North $20^{\circ}$ fault transmissivity $\left(\times 10^{-3} \mathrm{~m}^{2} / \mathrm{s}\right)$ & 1.14 & 1.1 & $\begin{array}{l}\text { (Le Borgne et al., 2004; Le Borgne et al., } \\
\text { 2006) }\end{array}$ \\
\hline Porosity $\varphi(\%)$ & 5 & 2.7 & (Leray et al., 2012) \\
\hline
\end{tabular}




\begin{tabular}{|c|c|c|}
\hline Sampling dates $t_{\mathrm{w}}$ & Acronym & Name and color for corresponding $p\left(t_{\mathrm{w}}-t\right)$ \\
\hline 1994 & $t_{\mathrm{w}}{ }^{1}$ & $p_{1=} p\left(t_{\mathrm{w}}{ }^{1}-t\right)$, blue \\
\hline 1994.1 & $t_{\mathrm{w}}^{2}$ & $P_{2=p}\left(t_{\mathrm{w}}{ }^{2}-t\right)$, wine \\
\hline 1995 & $t_{\mathrm{w}}{ }^{3}$ & $P_{3=} p\left(t_{\mathrm{w}}{ }^{3}-t\right)$, green \\
\hline 1999 & $t_{\mathrm{w}}^{4}$ & $p_{4=} p\left(t_{\mathrm{w}}{ }^{4}-t\right)$, not displayed \\
\hline 2004 & $t_{\mathrm{w}}^{5}$ & $p_{5=} p\left(t_{\mathrm{w}}^{5}-t\right)$, not displayed \\
\hline 2009 & $t_{\mathrm{w}}{ }^{6}$ & $p_{6=} p\left(t_{\mathrm{w}}{ }^{6}-t\right)$, not displayed \\
\hline
\end{tabular}



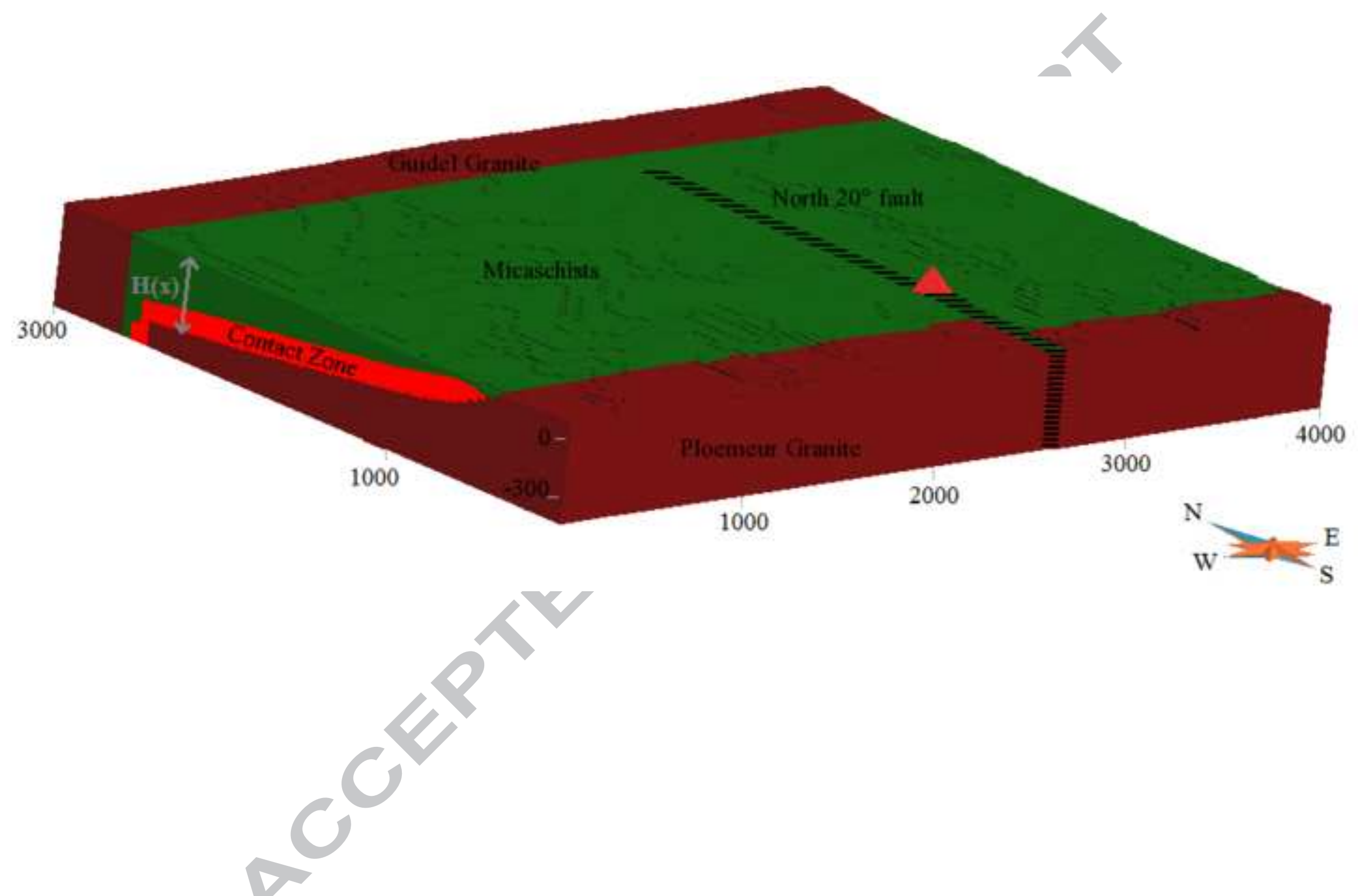


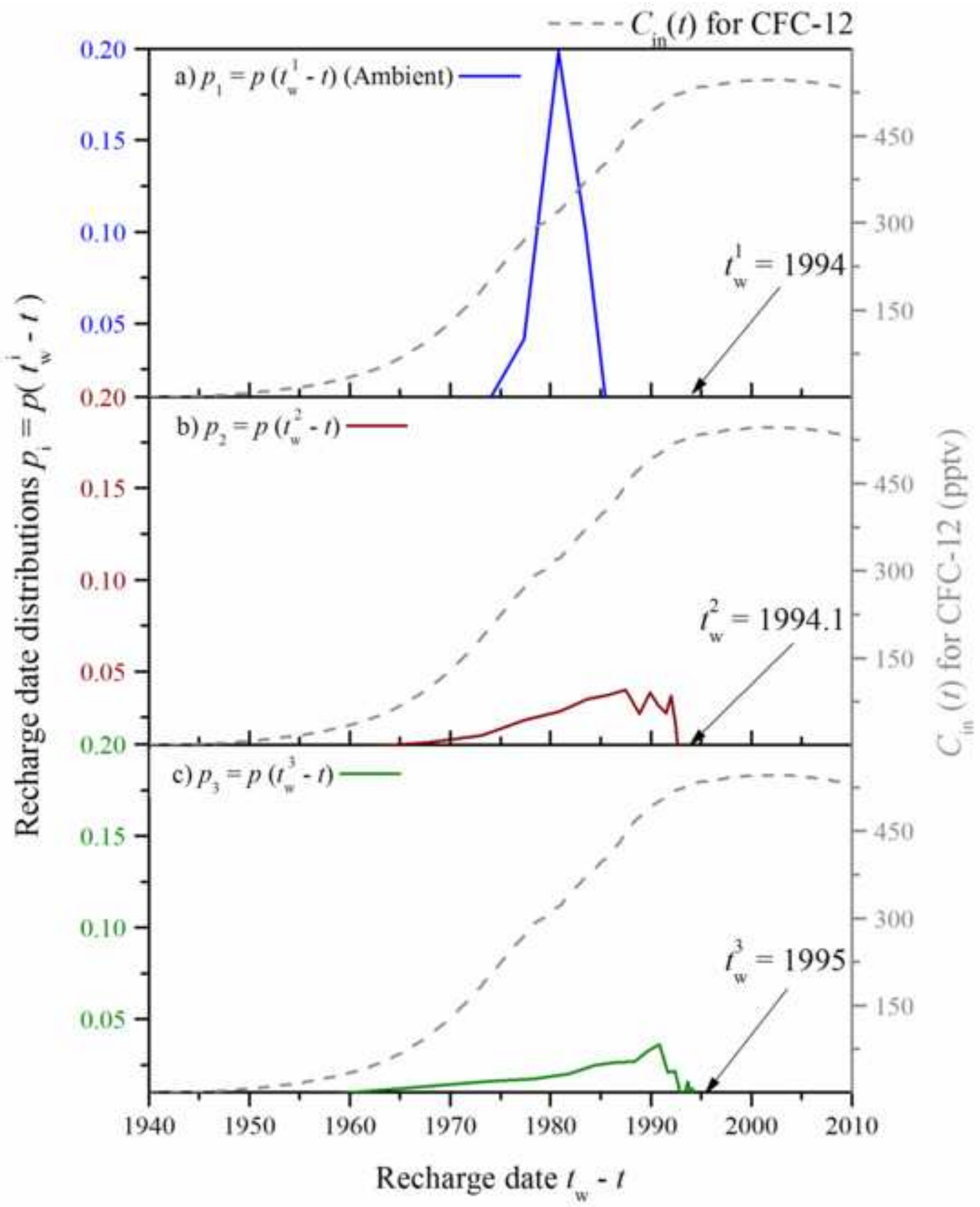




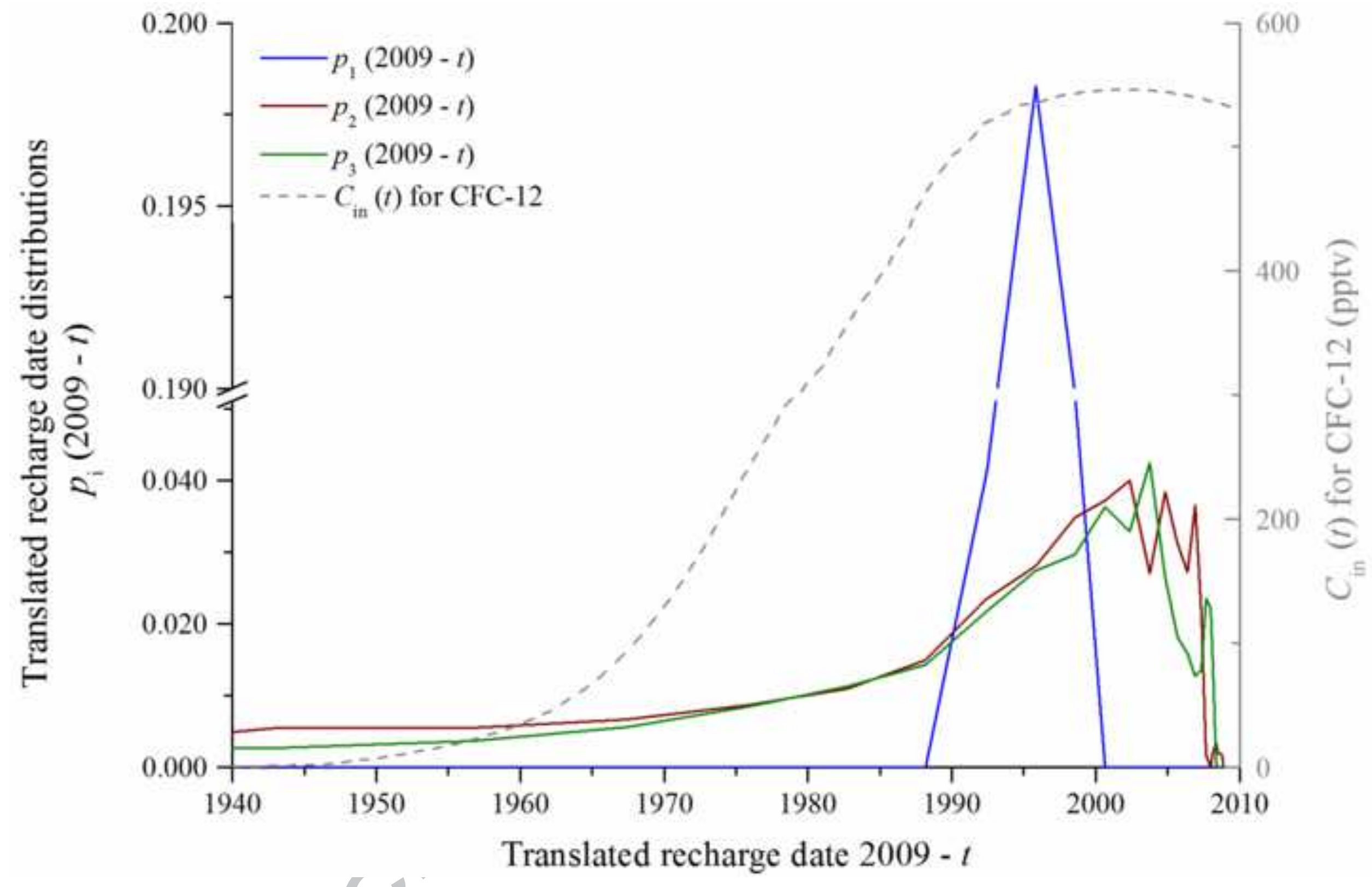




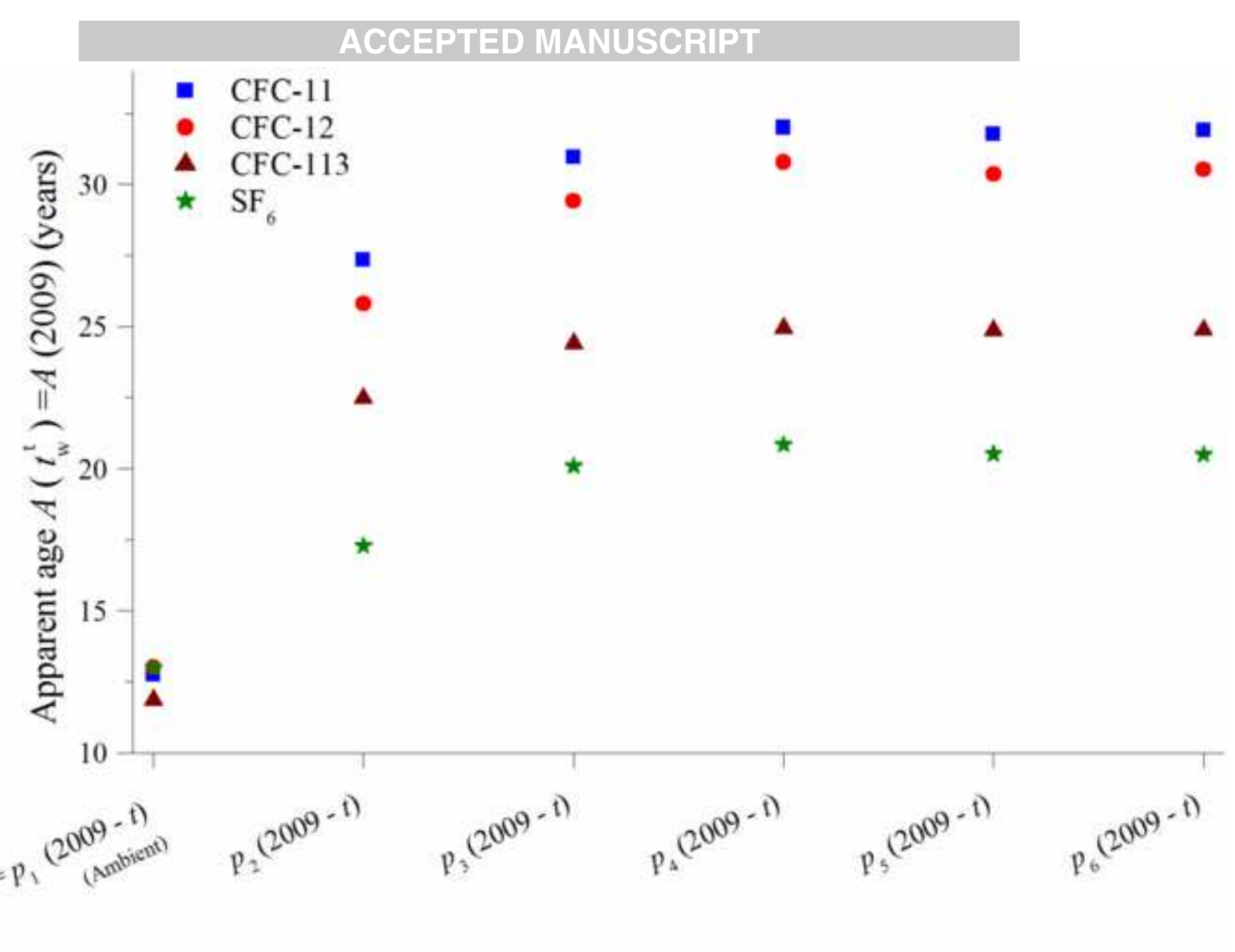

\section{Recharge date distributions}

$$
\text { Translated to } t_{\mathrm{w}}^{t}=2009
$$




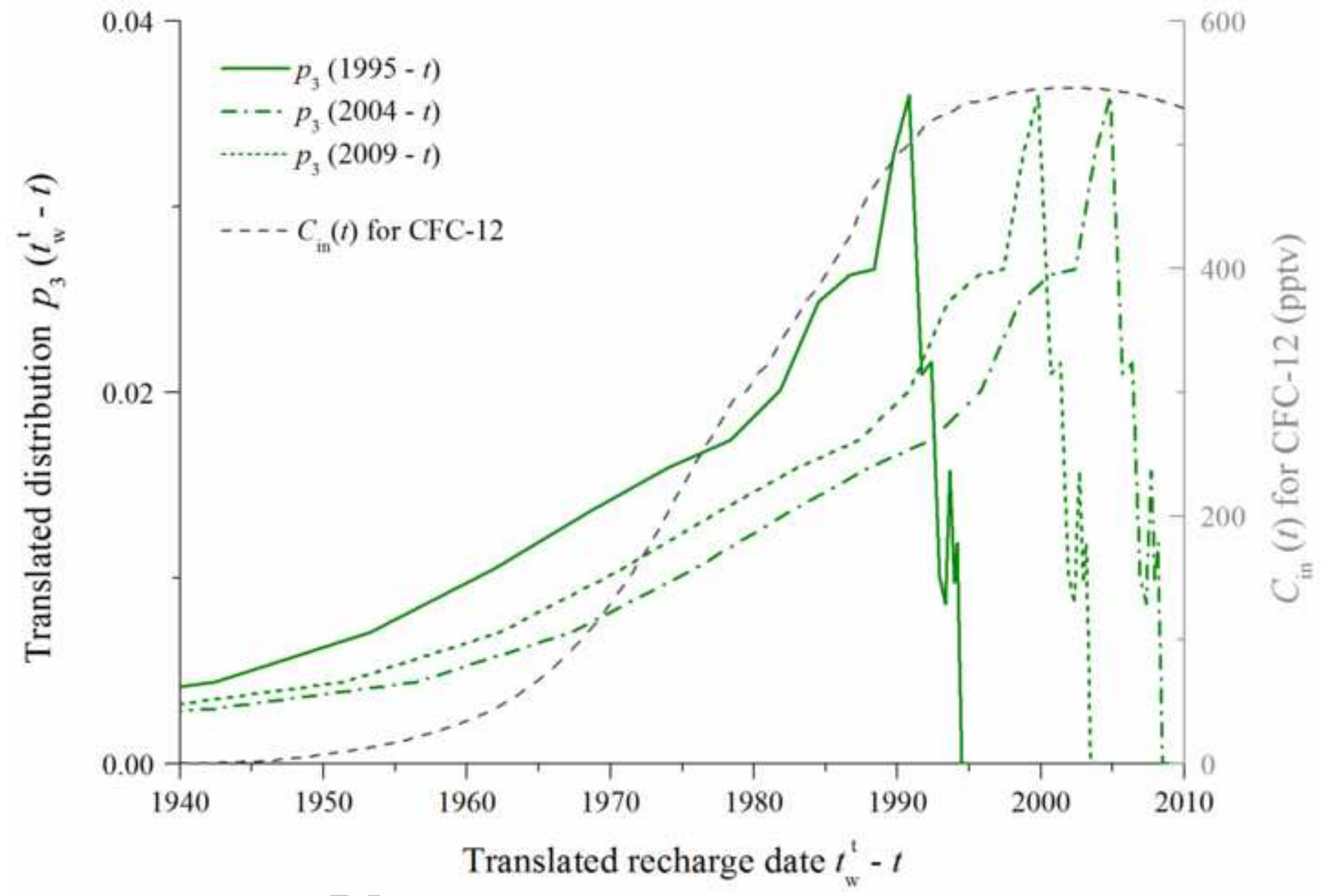




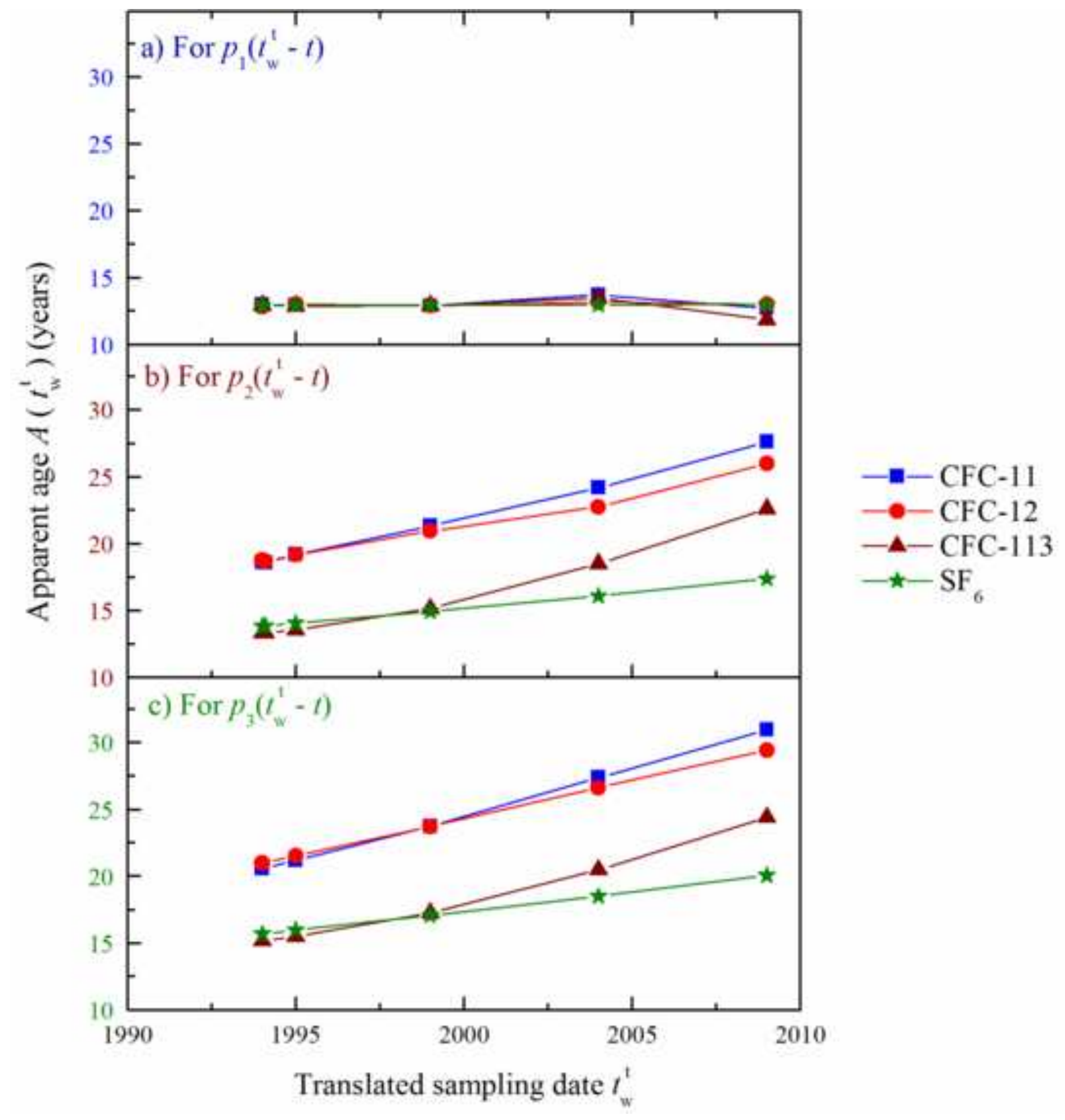

- CFC-12

- $-\mathrm{CFC}-113$

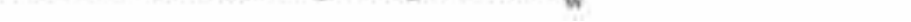




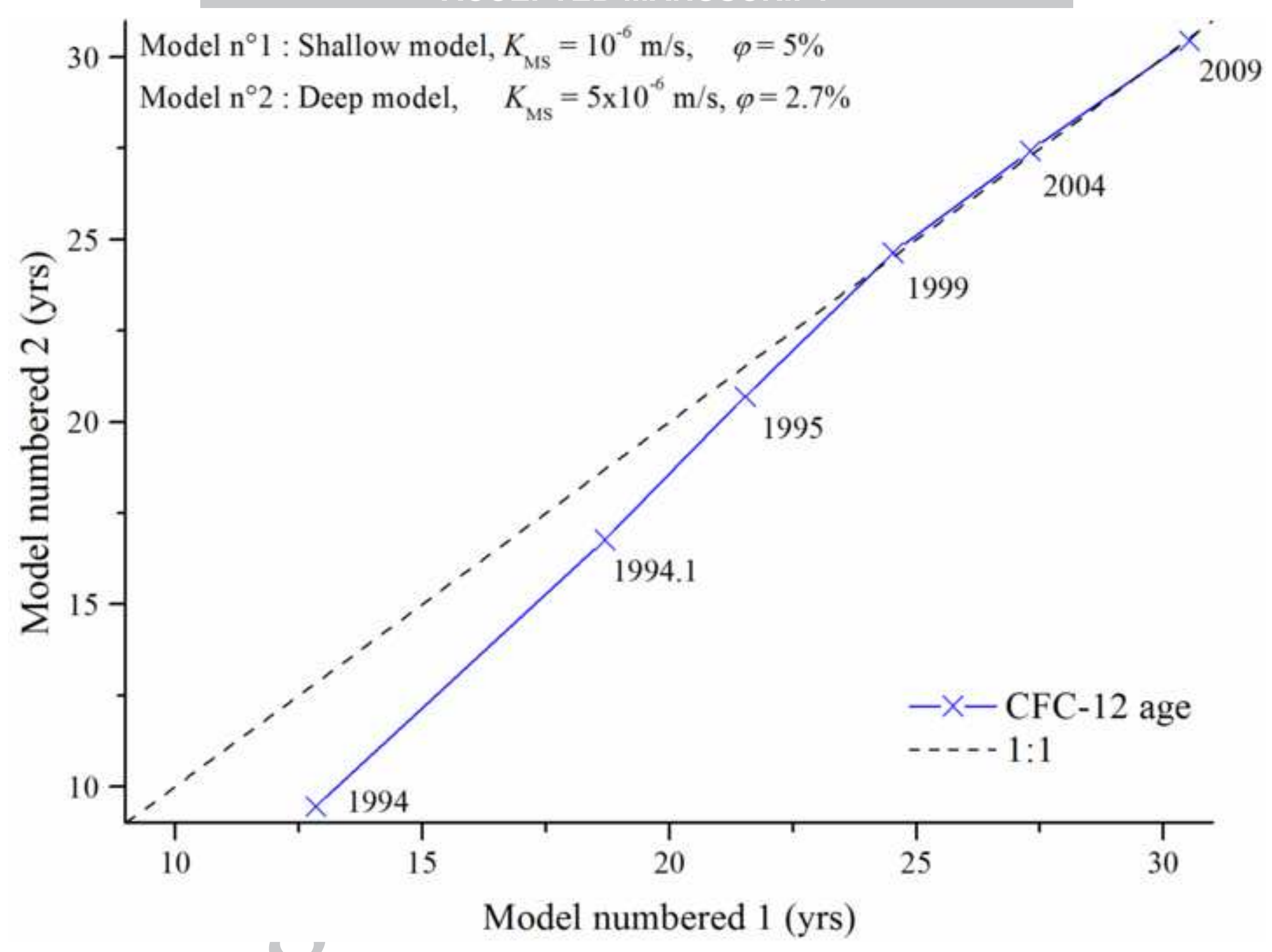


ACCEPTED MANUSCRIPT

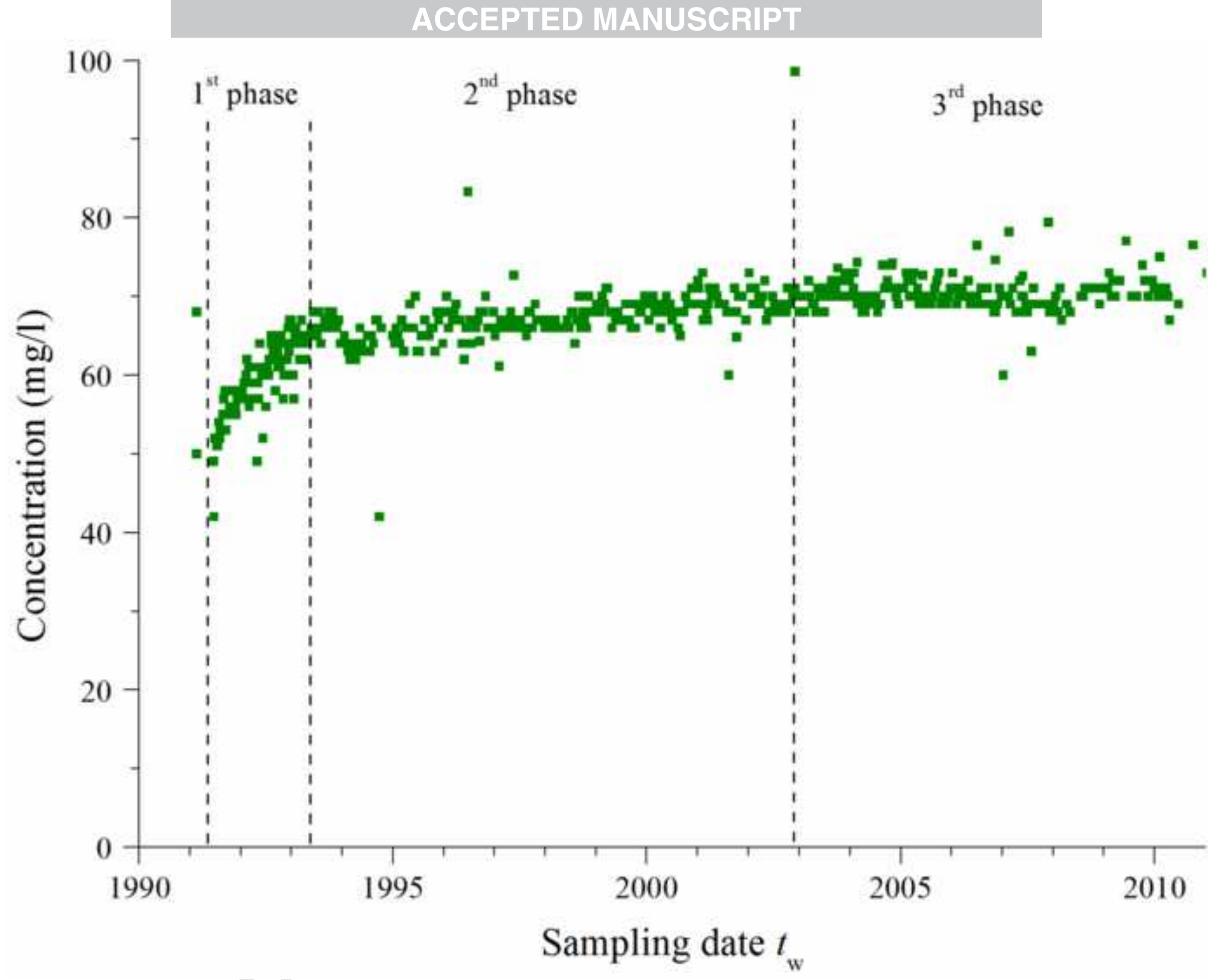




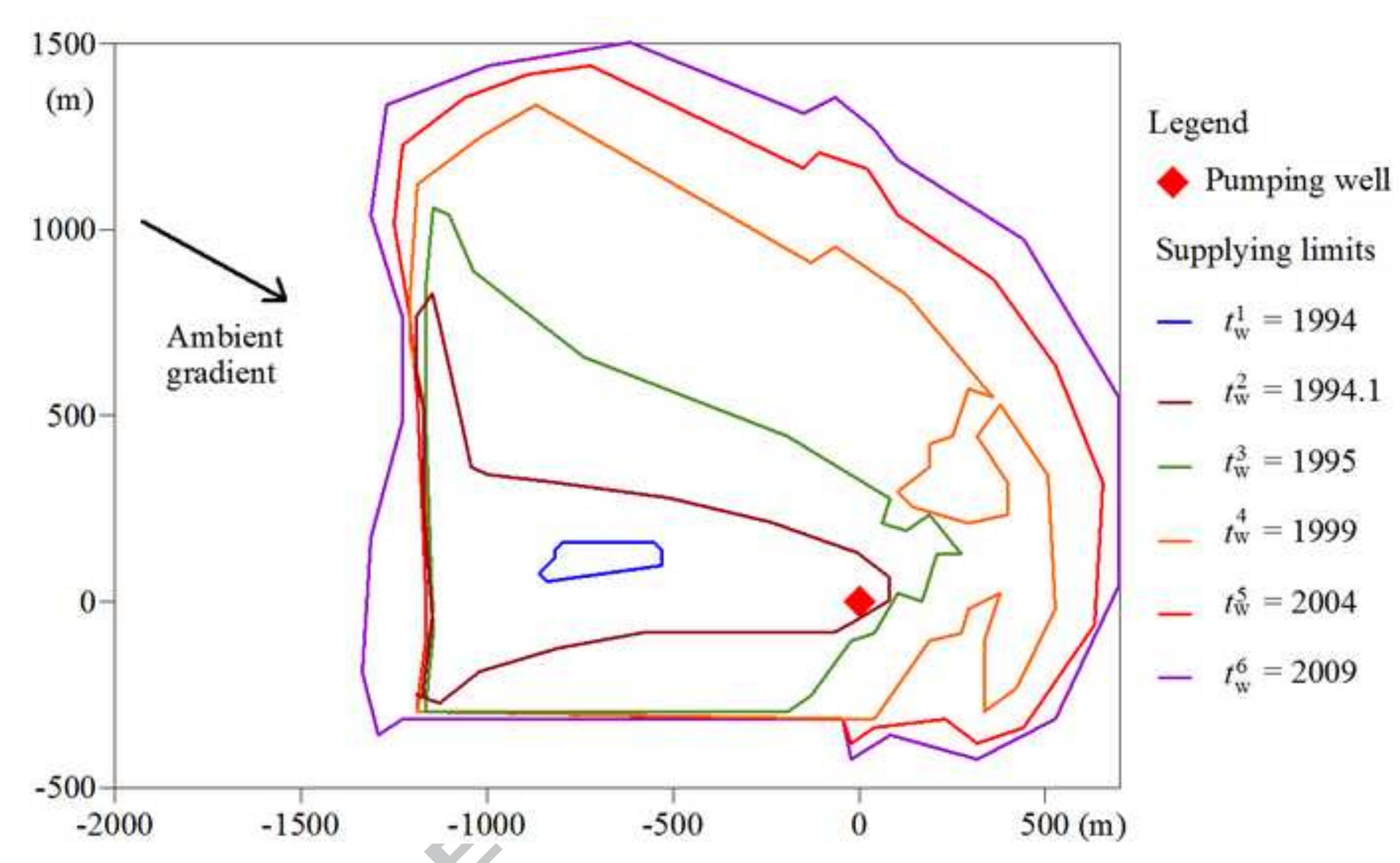




\section{Highlights:}

- Pumping start is modeled by an immediate shift between two steady-state flow fields

- Ages deduced from CFCs and $\mathrm{SF}_{6}$ concentrations evolve in two distinct phases

- Transient flow patterns affect ages just after the pumping start but quickly vanish

- Atmospheric concentrations then transiently weight the residence time distribution

- Similar in terms of magnitude, these two regimes are helpful for models segregation 